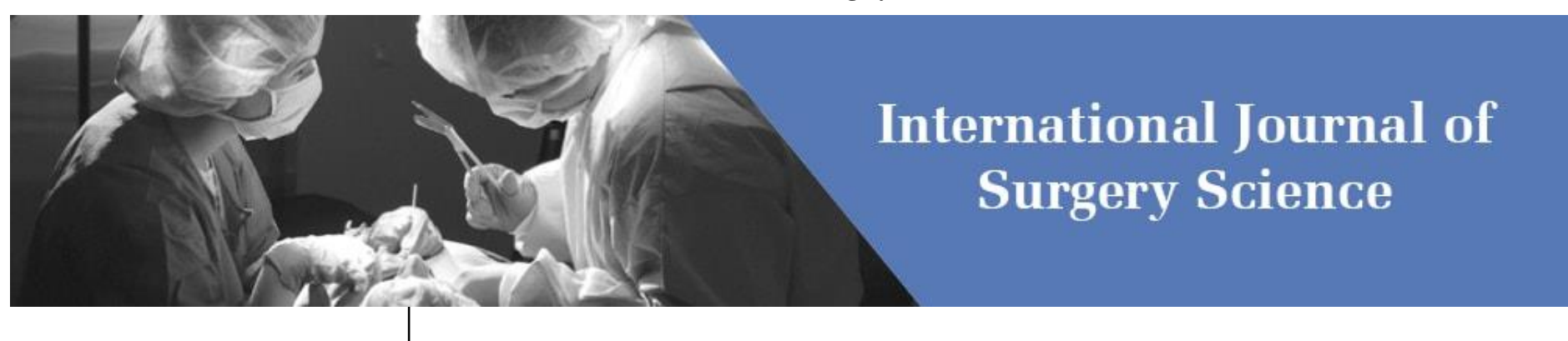

E-ISSN: 2616-3470

P-ISSN: 2616-3462

(C) Surgery Science

www.surgeryscience.com

2020; 4(3): 279-280

Received: 13-06-2020

Accepted: 23-07-2020

Dr. Harish Nayak Pangal

Associate Professor, Department of General Surgery, Srinivas Institute of Medical Sciences, Mangalore, India

Dr. Prashanth Kumar K Associate Professor, Department of General Surgery, Srinivas Institute of Medical Sciences, Mangalore, India
Corresponding Author: Dr. Prashanth Kumar K Associate Professor, Department of General Surgery, Srinivas Institute of Medical Sciences, Mangalore, India

\section{A study of magnesium therapy in diabetic foot care}

\author{
Dr. Harish Nayak Pangal and Dr. Prashanth Kumar K
}

DOI: https://doi.org/10.33545/surgery.2020.v4.i3e.508

\section{Abstract}

Background: Diabetes has been reported more in the last two decades probably because of the reach of primary health centers in our country. Yet this disease represents only the tip of iceberg of its actual size. This disease has been surprising us from a very long time and the more we know the more questions it throws at us. One such recent study suggests that magnesium supplementation helps in diabetics. This has been proved but does it help in controlling in diabetic foot disease is the question. This paper puts in an effort to find the answer.

Methods: Totally thirty patients were selected in the Department of General surgery who were admitted for diabetic foot. They were divided into two groups of fifteen each randomly and group 1 was given magnesium supplementation along with standard diabetic foot care and the other group was given only standard diabetic foot care. After a month the patients response to the same were compared.

Result: The patients in group 1 were benefitted and so the treatment was also offered to further patients. Conclusion: Magnesium therapy has a advantage in addition to the standard diabetic foot care.

Keywords: post, surgical, complications, inguinal hernia.

\section{Introduction}

Magnesium forms the the fourth largest content of cation in the human body and it is also the second most found intracellular cation is magnesium ${ }^{[1]}$. Total body content of the magnesium is about 25 grams in our body. About fifty to seventy percent is in combination with calcium in bone ${ }^{[2]}$. That means only about thirty percent is there present in Free State. It is also found in skeletal muscles ${ }^{[3]}$.

In diabetic patients its quantity is very less and firstly it was reported in children. In type 1 diabetics it has been reported in a lot of studies ${ }^{[4,5,6,7]}$. Actually the low levels of serum magnesium have been linked to a number of complications that is observed in diabetes mellitus. Reduced tyrosine kinase activity has been observed. Reduces sensitivity to insulin has been reported in studies and it was speculated due to decreased magnesium levels ${ }^{[8,9]}$. The low levels of serum magnesium may be due to glycosuria-related hypermagnesiuria, nutritional factors or hyperinsulinaemia. Other metabolism is also affected in diabetes especially the lipid metabolism. Magnesium supplementation is known to be beneficial for the same ${ }^{[10,11,12]}$. Does the magnesium supplementation help in controlling in diabetic foot disease is the question. This paper puts in an effort to find the answer.

\section{Aims and Objectives}

To study whether the magnesium supplementation help in controlling in diabetic foot disease.

\section{Materials and Methods}

This is a cross-sectional study which is randomized.

This study was done in the Department of Surgery, Srinivas Institute of Medical Sciences, Mangalore.

Thirty patients who underwent the open surgery were involved in the study. They were divided into two groups of fifteen each randomly and group 1 was given magnesium supplementation along with standard diabetic foot care and the other group was given only standard diabetic foot care. After a month the patient's response to the same were compared.

\section{Inclusion Criteria}

Only confirmed cases with active lesion on foot was involved. 


\section{Exclusion criteria}

Patients who were on immuno compromise drugs.

\section{Result}

Table 1: Sex distribution

\begin{tabular}{|c|c|}
\hline Male & 21 \\
\hline Female & 09 \\
\hline
\end{tabular}

In our study there were twenty one males and nine females.

Table 2: Age Distribution

\begin{tabular}{|c|c|}
\hline Mean age & SD \\
\hline 65.76 & \pm 7.87 years \\
\hline
\end{tabular}

The mean age of the subjects was found to be 65.76years with a standard deviation of \pm 7.87 years

Table 3: Mean magnesium levels before the treatment

\begin{tabular}{|c|c|}
\hline Group 1 & $1.85 \pm 0.71$ \\
\hline Group 2 & $1.79 \pm 0.41$ \\
\hline
\end{tabular}

The mean magnesium levels before the treatment was found to be $1.85 \pm 0.71$ in group 1 and $1.79 \pm 0.41$ in group 2 . There was no significant difference between the magnesium levels between the two groups.

Table 4: Mean Hospital stay after the magnesium therapy

\begin{tabular}{|c|c|}
\hline Group 1 & 24 \\
\hline Group 2 & 42.5 \\
\hline
\end{tabular}

The mean hospital stay for the treatment was found to be almost double in the second group.

Table 5: Mean Magnesium levels after the treatment

\begin{tabular}{|c|c|}
\hline Group 1 & $2.6 \pm 0.35$ \\
\hline Group 2 & $1.76 \pm 0.63$ \\
\hline
\end{tabular}

Ofcourse the magnesium level was found to be more in group one due to therapy effect and the second group was found to be almost the levels of the pre-procedure.

Table 6: Amputation

\begin{tabular}{|c|c|}
\hline Group 1 & 1 \\
\hline Group 2 & 3 \\
\hline
\end{tabular}

The amputations had to be carried out more in second group even after magnesium supplementation was given to the patients of second group after the study.

\section{Discussion}

There is a risk of low serum levels of magnesium, may it be Type 1 or 2 . And this causes insulin sensitivity problems in the receptors and thus the cycle continues. Lack of magnesium in the diet may not cause any symptoms because it has a dynamic relation with the stored magnesium in bones and skeletal muscle. But in diabetes the low serum levels are evident. It is also reported to be atherosclerotic. The lipid metabolism is destroyed slowly but surely because of the depletion of the magnesium in the serum. Recent studies in rats have shown that magnesium deficiency produces hypertriglyceridaemia, hypercholesterolemia, increased low-density lipoproteins (LDL), and reduced high-density lipoprotein (HDL) through reduced triglyceride clearance, diminished activity of lecithin cholesterol acetyltransferase (LCAT) and lipoprotein lipase, and increased activity of $\mathrm{HMG}-\mathrm{CoA}$ reductase.

In our study it is evident that replacing the magnesium by supplementation is beneficial in diabetic foot disease and this study is rather a boon to the patients.

\section{Conclusion}

Magnesium therapy has a advantage in addition to the standard diabetic foot care.

\section{References}

1. Vasudevan DM, Sreekumari S, Kannan Vaidyanathan. Textbook of Biochemistry. Jaypee 7th edn, 2013, 511-512.

2. Barton S Levine, Jack W Coburn M. Magnesium, the mimic/antagonist of calcium. New Engl J Med 1984; 310:1253-1254.

3. Gums JG. Clinical significance of magnesium: a review. Drug Intell Clin Pharm 1987; 21(3):240-246.

4. Maltezos E, Papazoglou D, Exiara $\mathrm{T}$ et al. Serum magnesium levels in non-diabetic offspring of patients with type 2 diabetes mellitus. Diabetes Nutr Metab 2004; 17(1):12-16.

5. Johansson G, Danielson BG, Ljunghall S, et al. Evidence for a disturbed magnesium metabolism in diabetes mellitus. Magnesium. 1981; 2:178-180.

6. Ewald U, Gebre Medhin M, Tuvemo T. Hypomagnesemia in diabetic children. Acta Paediat Scand 1983; 72(3):367371.

7. Tuvemo T, Ewald U, Kobbah M et al. Serum magnesium and protein concentrations during the first years of insulindependent diabetes in children. Acta Paediatric. 1997; 86(418):7-10.

8. Paolisso G, Barbagallo M. Hypertension, diabetes mellitus, and insulin resistance: the role of intracellular magnesium. Amer J Hypertens. 1997; 10(3):346-355.

9. Resnick LM. Cellular calcium and magnesium metabolism in the pathophysiology and treatment of hypertension and related metabolic disorders. Amer J Med 1992; 93(2A):11S$20 \mathrm{~S}$.

10. Hagg E et al. Magnesium therapy in type 1 diabetes. A doubleblind study concerning the effects on kidney function and serum lipid levels. Magnes Res. 1999; 12(2):123-130.

11. Corica F, Allegra A, Di Benedetto A et al. Effects of oral magnesium supplementation on plasma lipid concentrations in patients with non-insulin-dependent diabetes mellitus. Magnes Res. 1994; 7(1):43-47. 